\title{
Survival Rates and Factors Related to the Survival of Traffic Accident Patients Transported by Emergency Medical Services
}

\author{
Thongpitak Huabbangyang (D) \\ Rossakorn Klaiaungthong ${ }^{\prime}$ \\ Duangsamorn Jansanga ${ }^{2}$ \\ Airada Aintharasongkho ${ }^{2}$ \\ Tunwaporn Hanlakorn ${ }^{2}$ \\ Ratchanee Sakcharoen ${ }^{2}$ \\ Anucha Kamsom ${ }^{3}$ \\ Tavachai Soion ${ }^{4}$
}

'Department of Disaster and Emergency Medical Operation, Faculty of Science and Health Technology, Navamindradhiraj University, Bangkok, Thailand; ${ }^{2}$ Bachelor of Science Program in Paramedicine, Faculty of Medicine Vajira Hospital, Navamindradhiraj University, Bangkok, Thailand; ${ }^{3}$ Division of Biostatistic, Faculty of Medicine Vajira Hospital,

Navamindradhiraj University, Bangkok, Thailand; ${ }^{4}$ Division of Emergency Medical Service and Disaster, Faculty of Medicine Vajira Hospital, Navamindradhiraj University, Bangkok, Thailand
Correspondence: Rossakorn

Klaiaungthong

Tel +6622443878

Email rossakorn@nmu.ac.th
Background: Traffic accident patients place a tremendous burden on health care services because they require substantial, rapid, and effective evaluation, management, and treatment by emergency medical services (EMS) to decrease morbidity and mortality rates. This study investigated the 1-month survival rate and factors related to the survival of traffic accident patients managed by EMS.

Patients and Methods: We retrospectively analyzed data of traffic accident patients serviced by the Surgico Medical Ambulance and Rescue Team (SMART) at Vajira Hospital, Bangkok, from January 1, 2018, to December 31, 2020. The data were collected from EMS patient care reports recorded using the emergency medical triage protocol as well as the criteria-based dispatch response codes in Thailand. Survival data at 1 month were obtained from electronic medical records.

Results: Of the 340 traffic accident patients who fulfilled the study criteria, $314(92.35 \%)$ were alive at 1 month. A multivariable analysis using multiple logistic regression identified prehospital level of consciousness, airway management, and cardiopulmonary resuscitation as factors associated with survival. Unresponsive patients had a lower survival rate than responsive patients (adjusted odds ratio $\left[\mathrm{OR}_{\mathrm{adj}}\right]=0.16,95 \%$ confidence interval $[\mathrm{CI}]: 0.05-$ $0.56, \mathrm{p}=0.004)$. Prehospital airway management and cardiopulmonary resuscitation reduced the survival rate by 0.30 and 0.10 times, respectively $\left(\mathrm{OR}_{\mathrm{adj}}=0.30,95 \% \mathrm{CI}: 0.09-0.97, \mathrm{p}=\right.$ 0.045 and $\mathrm{OR}_{\mathrm{adj}}=0.10,95 \% \mathrm{CI}: 0.02-0.47, \mathrm{p}=0.004$, respectively).

Conclusion: Traffic accident patients had a high survival rate at 1 month. We identified three factors regarding EMS treatment which were related to increased survival: a prehospital responsive level of consciousness, no prehospital airway management, and no prehospital cardiopulmonary resuscitation. Therefore, the development of standard guidelines for the management of traffic accident patients by EMS is crucial to increase the survival rate of traffic accident patients.

Keywords: EMS, level of consciousness, airway management, cardiopulmonary resuscitation

\section{Introduction}

The mortality rate of patients involved in traffic accidents severely impacts individuals, communities, societies, and nations. Traffic accidents place a global burden on health care services, affecting both societal and economic factors, as well as impeding country development. According to the World Health Organization, Thailand has the highest traffic accident mortality rate in Asia and the second highest globally in 2015. ${ }^{1}$ The mortality rate of traffic accidents in low- to middle-income countries is $90 \%{ }^{2}$ Emergency medical services (EMS) data from all 77 provinces of Thailand 
obtained from the Information Technology for Emergency Medical System, a national database for prehospital care, shows that the number of response code 25 (motor vehicle accident) criteria based dispatch (CBD) services has increased each year from 2016 to $2020 .^{3}$ However, The Injury Data Collaboration Center of the Division of Injury Prevention reported a decrease in the traffic accident mortality rate in Thailand during 2016-2019. ${ }^{4}$

An EMS has been set up and integrated into existing health care systems to minimize morbidity and mortality by providing pre-hospital treatments and transportation to the most appropriate hospital. ${ }^{5}$ Traffic accidents require experts in patient management, handling accidents and disasters, and treating critical emergency medical conditions. EMS are a modern healthcare service tasked with reducing the rate of prehospital morbidity and mortality. ${ }^{6-8}$ The main principle of the management of injured patients due to accidents is correctness. Prehospital, injured patients are managed according to two essential concepts: the golden period or golden hour and the platinum 10 minutes. The golden period refers to the 60 minutes from the time of the accident to receiving definitive care, after which morbidity and mortality significantly increase. Coupled with the golden hour, the platinum 10 minutes refers to paramedics having at most 10 minutes at the scene to manage severely injured patients to improve the rate of survival. ${ }^{8}$ Many studies have focused on the survival of patients with general injuries. ${ }^{9-11}$ A study of motor vehicle accidents conducted in the United States reported that the longer the time taken at the scene, the higher the rate of mortality rate. ${ }^{12}$

In a previous study, for traffic accident patients' characteristics and outcomes, EMS patients tended to have poorer Glasgow coma scale (GCS) and hemodynamic measures, compared to non-EMS patients. However, no patient factor affecting survival was reported in the study. ${ }^{13}$ A limited number of studies have investigated the survival rate and factors related to the survival of traffic accident patients managed by EMS in Thailand, particularly in Bangkok, the capital city. To add to the body of knowledge, this study investigated the 1-month survival rate and associated factors related to the survival of traffic accident patients managed by EMS in zone 1 of the Bangkok EMS area.

\section{Methods}

\section{Study Design and Setting}

This retrospective cohort study was researched at the Surgico Medical Ambulance and Rescue Team (SMART), Faculty of
Medicine Vajira Hospital, Navamindradhiraj University, Thailand, which is situated in zone 1 of the Bangkok EMS area from a total of nine areas that are dispatched by the Bangkok EMS dispatch center (Erawan Center). This dispatch center also receives emergency calls, and traffic accident services are its fourth-busiest service. The study period was from January 1, 2018, to December 31, 2020 (3 years). SMART is responsible for $50 \mathrm{~km}^{2}$, serving a population of $>500,000$ people around-the-clock. This area covers six hospitals, including both public and private ones, which have been overseen and serviced since 1985 .

\section{Population}

Data of patients involved in traffic accidents were collected from EMS patient care reports recorded using the emergency medical triage protocol as well as CBD RCs 25 red 1-25 red 5, managed by SMART, Faculty of Medicine Vajira Hospital.

\section{Eligibility Criteria}

Traffic accident patients aged $>18$ years whose treatment was recorded using the emergency medical triage protocol as well as CBD RCs 25 red $1-25$ red 5 and who were serviced by SMART, Faculty of Medicine Vajira Hospital, and sent to the emergency department of Faculty of Medicine Vajira Hospital were eligible for study enrolment.

\section{Exclusion Criteria}

The injured who were dead at the scene, those without complete data, and those denied treatment and transportation were excluded.

\section{Sample Size Determination}

We investigated the 1-month survival rate and factors related to the survival of traffic accident patients managed by EMS. The primary outcome was the 1-month survival rate, and the sample size estimation was calculated using a population proportion formula. ${ }^{14}$ The confidence interval (CI) was $95 \%$, with an error margin of $2 \%$. The proportion (survival rate of traffic accident patients managed by EMS) was taken as $98.56 \%$, as referred to in a previous study. ${ }^{15}$ The calculated sample size was at least 137 . We used two independent proportions ${ }^{16}$ to calculate the sample size for the secondary outcomes (factors related to survival). The 1-month survival rates of responsive and unresponsive patients were $99.5 \%$ and $86.5 \%$, respectively, as previously reported. ${ }^{13}$ The ratio of responsive to unresponsive patients was 0.126 (301 responsive and 38 unresponsive patients), as 
recorded in the medical records of motor vehicle accident patients serviced by SMART, Faculty of Medicine Vajira Hospital. A CI of $95 \%$ and a power of $80 \%$ were used to calculate a sample size of no less than 156 and 20 for responsive and unresponsive patients, respectively (total sample size $=176$ ). We added $20 \%$ of the sample size to compensate for incomplete data using the formula $\mathrm{n}_{\text {new }}=$ $176 /(1-0.2),{ }^{17}$ resulting in a final sample size of at least 220. From January 1, 2018, to December 31, 2020, 340 patients met these criteria.

\section{Operational Definitions}

1. The RC was defined as one of 25 severity codes assigned at the scene, derived from acquiring patients' symptoms from informers. RC 25 refers to a traffic or motor vehicle accident, defined as injury due to motor vehicle usage, pedestrian crash, or motorcycle crash. The RC 25 red included red $1-$ red $5 .{ }^{18}$

2. The 1-month survival rate was defined as the survival of traffic accident patients (RC 25 red) serviced by EMS. The day that the patient received the service was considered day 1 . Survival was evaluated on day 28 using information obtained from EMS patient care reports and electronic medical records from the Faculty of Medicine Vajira Hospital.

3. The response time was defined as the time elapsed between the emergency call to the arrival of the ambulance at the scene.

4. On-scene time was defined as the duration from the time of ambulance arrival at the scene to its departure from the scene.

5. Prehospital level of consciousness was defined as an assessment of the patient's level of consciousness as per the AVPU scale $(\mathrm{A}=$ alert, $\mathrm{V}=$ verbal, $\mathrm{P}=$ pain, $\mathrm{U}=$ unresponsive). Patients who were alert, verbal, and responsive to pain were assigned to the responsive group, whereas patients who were unresponsive were assigned to the unresponsive group.

\section{Data Collection Tools, Procedures, and Quality Control}

Data were collected from EMS patient care reports, a standard operational report of advanced EMS, Bangkok EMS dispatch center (Erawan Center), which is also used for the disbursement of emolument to paramedics. The reports were retrospectively collected by one author who input the data on a Excel. This eliminated the need to evaluate interrater reliability. The data were amassed in
Microsoft Excel (Microsoft, Redmond, WA, USA). This included patient data (gender, age, prehospital systolic blood pressure, prehospital heart rate, prehospital oxygen saturation, prehospital level of consciousness, type of wounds, type of orthopedic injuries, type of hemorrhage, and body part injured), EMS data (RC, response time, onscene time, distance from base station to scene, and distance from scene to hospital), treatment data (prehospital hemorrhage control, prehospital airway management, prehospital fluid management, prehospital immobilization, and prehospital cardiopulmonary resuscitation), and hospital follow-up data at 1 month (survival).

\section{Data Processing and Analysis}

We used descriptive statistics to analyze the collected data. First we quantitatively analyzed the patient and treatment data, and the results were expressed as the frequency distribution and percentage. Then, we performed a quantitative analysis of the EMS data. The results were expressed as means \pm standard deviation (SD) or median and interquartile range (IQR), as appropriate. The 1-month survival rate of traffic accident patients serviced by EMS was reported as the frequency distribution and percentage (incidence rate) as well as the $95 \%$ CI. The factors related to survival were described using the frequency distribution and percentage as well as either the Chi-square test or Fisher exact test for crude analysis. Multivariable analysis was performed using multivariable logistic regression backwards stepwise regression and reported as the odds ratio (OR) and $95 \% \mathrm{CI}$.

All statistical analyses were performed using IBM SPSS Statistics for Windows v26.0. (IBM Corp., Armonk, NY, USA). A p-value $\leq 0.05$ was considered statistically significant.

\section{Ethics Approval and Consent to Participate}

This study was approved by the Institutional Review Board of the Faculty of Medicine Vajira Hospital, Navamindradhiraj University (No. COA. 164/2564).

\section{Results \\ General Data and I-Month Survival Rate of Traffic Accident Patients Managed by EMS}

The survival rate at 1 month of the 340 traffic accident patients in our study cohort was $92.35 \%$ (95\% CI: 89.00 
94.94). The majority of patients in both the alive and dead groups were male $(71.0 \%$ and $73.1 \%$, respectively; $\mathrm{p}=$ 0.824 ), and the mean age \pm SD of the alive and dead groups was $37.33 \pm 16.99$ and $33.85 \pm 17.00$ years, respectively $(\mathrm{p}=0.316)$. A prehospital systolic blood pressure $>90 \mathrm{mmHg}$ was observed in $93.9 \%$ of the patients in the alive group and only $50.0 \%$ of the patients in the dead group ( $\mathrm{p}<0.001$ ). A prehospital oxygen saturation $>94 \%$ on room air was observed in $83.4 \%$ of patients in the alive group and $57.7 \%$ of patients in the dead group $(p<0.001)$. The prehospital level of consciousness was recorded as responsive in $93.3 \%$ of patients in the alive group. On the other hand, the prehospital level of consciousness was recorded as unresponsive in $65.4 \%$ of the patients in the dead group $(\mathrm{p}<0.001)$ (Table 1$)$.

Regarding the $\mathrm{RC}, 49.0 \%$ of the alive group were classified as RC 25 red 4, whereas $42.3 \%$ of the dead group were classified as RC 25 red 1 ( $p<0.001)$. The median on-scene time was $7 \mathrm{~min}(\mathrm{IQR}=4-9)$ and $8.5 \mathrm{~min}$ (IQR $=6-13$ ) for the alive and dead groups, respectively $(\mathrm{p}=0.012)$. The patients in the alive and dead groups had an on-scene time of not more than $10 \mathrm{~min}(82.5 \%$ and $61.5 \%$, respectively, $\mathrm{p}=0.017$ ).

Prehospital airway management was necessary in $30.3 \%$ and $80.8 \%$ of the patients in the alive and dead groups, respectively $(\mathrm{p}<0.001)$, which included a mask with bag (23.6\% and $11.5 \%$, respectively; $p=0.159)$, bag valve mask (6.4\% and $61.5 \%$, respectively; $p<0.001)$, and endotracheal tube $(0.6 \%$ and $15.4 \%$, respectively; $\mathrm{p}<$ $0.001)$. Prehospital cardiopulmonary resuscitation was performed on $1.0 \%$ and $42.3 \%$ of patients in the alive and dead groups, respectively $(\mathrm{p}<0.001)$ (Table 2$)$.

\section{Factors Associated with Survival of Traffic Accident Patients Managed by EMS}

We performed univariable analyses using binary logistic regression analysis. The results revealed that prehospital systolic blood pressure ( $>90 \mathrm{mmHg}$ : OR $=15.53,95 \% \mathrm{CI}$ : 6.33-38.11, p <0.001), prehospital oxygen saturation $(>94 \%$ on room air: $\mathrm{OR}=6.87,95 \%$ CI: $2.99-15.8$, $\mathrm{p}<0.001$ ), prehospital level of consciousness (OR = 0.04, 95\% CI: $0.02-0.10, \mathrm{p}<0.001$ ), facial injury (OR = $0.30,95 \%$ CI: $0.14-0.69, \mathrm{p}=0.004), \mathrm{RC} 25$ red (code 3 : $\mathrm{OR}=4.30,95 \% \mathrm{CI}: 1.61-11.43, \mathrm{p}=0.004$; code 4-5: OR $=7.00,95 \%$ CI: $2.52-19.40, \mathrm{p}<0.001)$, on-scene time ( $\leq 10 \mathrm{~min}:$ OR $=2.94,95 \%$ CI: $1.27-6.83, \mathrm{p}=0.012$ ), prehospital airway management $(\mathrm{OR}=0.10,95 \% \mathrm{CI}$ :
0.04-0.28, p <0.001), prehospital fluid management (OR $=0.24,95 \%$ CI: $0.11-0.57, \mathrm{p}=0.001)$, and prehospital cardiopulmonary resuscitation (OR $=0.01,95 \%$ CI: $0.01-$ $0.05, \mathrm{p}<0.001)$ were significant factors related to the survival of traffic accident patients managed by EMS (Tables 3 and 4).

Multivariable analysis was performed using multiple logistic regression analysis of the significant factors that were identified as related to the survival of traffic accident patients managed by EMS. Next, we performed a backward stepwise selection with a p-value of 0.05 defined as significant. The significant factors identified included prehospital level of consciousness (the unresponsive group had a survival rate 0.16 times lower than the responsive group; adjusted OR $\left[\mathrm{OR}_{\mathrm{adj}}\right]=0.16,95 \% \mathrm{CI}$ : $0.05-0.56, \mathrm{p}=0.004)$, prehospital airway management (the group with airway management had a survival rate 0.30 times lower than the group with no airway management; $\mathrm{OR}_{\mathrm{adj}}=0.30,95 \% \mathrm{CI}: 0.09-0.97, \mathrm{p}=0.045$ ), and prehospital cardiopulmonary resuscitation (the group with resuscitation had a survival rate 0.10 times lower than the group without resuscitation; $\mathrm{OR}_{\mathrm{adj}}=0.10,95 \% \mathrm{CI}$ : 0.02 $0.47, \mathrm{p}=0.004)$ ] (Table 5).

\section{Discussion}

The survival rate of traffic accident patients managed by EMS at 1 month was $92.35 \%$. The factors related to survival included a prehospital responsive level of consciousness, no prehospital airway management, and no cardiopulmonary resuscitation.

Although the 1-month survival rate was very high, it was comparable to the findings of Wongvatanakij et al, ${ }^{19}$ who reported a survival rate of $97.9 \%$ for traffic accident patients who were treated in a tertiary hospital in Thailand, a study by Tesfay et $a{ }^{20}{ }^{20}$ who reported that survival for traffic accident patients was quite good and had a short recovery time, and a study by Seid et al, ${ }^{21}$ who reported a mortality rate of $7.4 \%$ for traffic accident patients in an emergency department in Addis Ababa, Ethiopia.

We only included data of severely injured patients with RC 25 red 1-red 5 and excluded those with code yellow or green because SMART only serviced only patients with code red (severe injury), and these patients were transported to the emergency department of Vajira Hospital, a level 2 trauma and university hospital in Bangkok. Therefore, it could be implied that the high 1-month survival rate was thanks to the effective management of the EMS team, the emergency department, and the hospital. 
Table I Characteristics of the Traffic Accident Patients in Our Cohort $(N=340)$

\begin{tabular}{|c|c|c|c|c|c|}
\hline Variables & \multicolumn{2}{|c|}{ Alive $(n=314)$} & \multicolumn{2}{|c|}{ Dead $(n=26)$} & p-value \\
\hline \multicolumn{6}{|l|}{ Gender } \\
\hline Male & 223 & $(71.0)$ & 19 & $(73.1)$ & 0.824 \\
\hline Female & 91 & $(29.0)$ & 7 & $(26.9)$ & \\
\hline Age (years), mean $\pm S D$ & \multicolumn{2}{|c|}{$37.33 \pm 16.99$} & \multicolumn{2}{|c|}{$33.85 \pm 17.00$} & 0.316 \\
\hline \multicolumn{6}{|c|}{ Prehospital systolic blood pressure $(\mathrm{mmHg})$} \\
\hline$\leq 90$ & 19 & $(6.1)$ & 13 & $(50.0)$ & $<0.001$ \\
\hline$>90$ & 295 & $(93.9)$ & 13 & $(50.0)$ & \\
\hline \multicolumn{6}{|l|}{ Prehospital heart rate (bpm) } \\
\hline$\leq 100$ & 213 & $(67.8)$ & 14 & $(53.8)$ & 0.146 \\
\hline$>100$ & 101 & $(32.2)$ & 12 & $(46.2)$ & \\
\hline \multicolumn{6}{|c|}{ Prehospital oxygen saturation on room air } \\
\hline$\leq 94 \%$ & 52 & $(16.6)$ & 15 & $(57.7)$ & $<0.001$ \\
\hline$>94 \%$ & 262 & $(83.4)$ & $\mathrm{II}$ & $(42.3)$ & \\
\hline \multicolumn{6}{|c|}{ Prehospital level of consciousness } \\
\hline Responsive & 293 & $(93.3)$ & 9 & $(34.6)$ & $<0.001$ \\
\hline Unresponsive & 21 & $(6.7)$ & 17 & $(65.4)$ & \\
\hline Wounds & 285 & $(90.8)$ & 23 & $(88.5)$ & 0.724 \\
\hline Cut/laceration & 164 & $(52.2)$ & 13 & $(50.0)$ & 0.827 \\
\hline Abrasion & 142 & $(45.2)$ & 16 & $(61.5)$ & 0.109 \\
\hline Contusion & 126 & $(40.1)$ & 11 & $(42.3)$ & 0.828 \\
\hline Amputation & I & $(0.3)$ & 0 & $(0.0)$ & 1.000 \\
\hline Orthopedic injuries & 173 & $(55.1)$ & 14 & $(53.8)$ & 0.902 \\
\hline Close fracture & 120 & $(38.2)$ & 11 & $(42.3)$ & 0.680 \\
\hline Open fracture & 55 & $(17.5)$ & 5 & $(19.2)$ & 0.791 \\
\hline Dislocation & 13 & $(4.1)$ & 0 & $(0.0)$ & 0.610 \\
\hline Hemorrhage & 121 & $(38.5)$ & 12 & $(46.2)$ & 0.444 \\
\hline Externally stopped & 91 & $(29.0)$ & 9 & $(34.6)$ & 0.545 \\
\hline Externally active & 23 & $(7.3)$ & I & (3.8) & 1.000 \\
\hline Internal hemorrhage & 12 & (3.8) & 2 & (7.7) & 0.291 \\
\hline \multicolumn{6}{|l|}{ Body part injured } \\
\hline Extremity & 209 & $(66.6)$ & 17 & $(65.4)$ & 0.903 \\
\hline Head/neck & 170 & $(54.1)$ & 16 & $(6 \mid .5)$ & 0.466 \\
\hline Face & 92 & $(29.3)$ & 15 & $(57.7)$ & 0.003 \\
\hline
\end{tabular}


Table I (Continued).

\begin{tabular}{|c|c|c|c|c|c|}
\hline \multirow{2}{*}{$\begin{array}{l}\text { Variables } \\
\text { Chest/clavicle }\end{array}$} & \multicolumn{2}{|c|}{ Alive $(n=314)$} & \multicolumn{2}{|c|}{ Dead $(n=26)$} & \multirow{2}{*}{$\frac{p \text {-value }}{0.119}$} \\
\hline & 37 & $(I I .8)$ & 6 & $(23.1)$ & \\
\hline External body surface & 27 & $(8.6)$ & 2 & (7.7) & 1.000 \\
\hline Pelvis & 27 & $(8.6)$ & 2 & (7.7) & 1.000 \\
\hline Multiple injuries & 24 & (7.6) & 3 & $(11.5)$ & 0.448 \\
\hline Abdomen & 22 & $(7.0)$ & 2 & (7.7) & 0.704 \\
\hline Spine & 18 & (5.7) & 2 & (7.7) & 0.658 \\
\hline
\end{tabular}

Notes: Data are presented as number (\%), mean \pm SD or median (interquartile range). P-values correspond to the independent sample $t$-test, Mann-Whitney U-test, Chisquare test, or Fisher exact test.

Abbreviations: bpm, beats per minute; NA, data not applicable; SD, standard deviation.

However, we only studied factors concerning EMS. SMART, Faculty of Medicine Vajira Hospital, is an advanced life support unit. Emergency physicians, paramedics, emergency nurse practitioners, and emergency medical technicians are included in each emergency medical operation. In Thailand, both the Anglo-American and Franco-German emergency services system models are applied. The EMS team uses online and offline protocols under the instruction of the medical director. ${ }^{22}$

Our findings revealed that a prehospital responsive level of consciousness affected the survival rate. This correlated with the findings of Mahama et $\mathrm{al}^{15}{ }^{15}$ who reported that the survival rate of patients with a prehospital responsive level of consciousness was $99.5 \%$, while that of patients with a prehospital unresponsive level of consciousness was $86.5 \%$. Moreover, the unresponsive patients typically had severe and critical injuries. The reason why patients without prehospital airway management have a higher rate of survival is probably because patients who are intubated at the scene always have severe symptoms or receive prehospital cardiopulmonary resuscitation, leading to a poor outcome. However, Hoffmann et $\mathrm{al}^{23}$ reported that patients with a Glasgow coma scale $\leq 8$ who were intubated in the field appeared to have a better outcome compared with those without intubation, and prehospital intubation for indicated patients might decrease the mortality rate and improve early neurologic outcomes. This correlated with a study by Denninghoff et al, ${ }^{24}$ who reported that prehospital intubation was associated with a good outcome and decreased mortality rate and was not associated with increased illness and death.
Another important finding of our study was that patients who received prehospital cardiopulmonary resuscitation had a survival rate 0.1 times lower than those who did not need to be resuscitated. A possible explanation is that the patients who received prehospital cardiopulmonary resuscitation at the scene died in 1-2 days upon hospital arrival, which was comparable to the findings of Dorlac et al, ${ }^{25}$ who reported that all patients who received prehospital cardiopulmonary resuscitation died, and those of Stewart et $\mathrm{al}^{26}{ }^{26}$ who found that most of the deceased were severely injured and had received advanced lifesaving medical procedures, including prehospital intubation and cardiopulmonary resuscitation. Furthermore, Stockinger et $\mathrm{al}^{27}$ reported that only 22 of $588(3.7 \%)$ patients who received prehospital cardiopulmonary resuscitation survived and were discharged from hospital, and Alanezi et $\mathrm{al}^{28}$ reported an overall mortality rate of $96 \%$ in 50 patients who received prehospital cardiopulmonary resuscitation, with only two patients surviving and being discharged from hospital. Most of the abovementioned studies were related to many different mechanisms of injury, so it was unclear whether traffic accident patients with prehospital cardiopulmonary resuscitation had poorer outcomes.

\section{Study Strengths and Limitations}

The strength of this study is that our findings will be instrumental in improving EMS management of traffic accident patients, thereby increasing the survival rate. Our findings can be used to develop standard guidelines for EMS for the management of traffic accident patients to increase their rate of survival. Our study had several limitations. Firstly, most patients (314 of 340) survived, 
Table 2 Characteristics of the EMS Unit and Treatment in Our Cohort $(\mathrm{N}=340)$

\begin{tabular}{|c|c|c|c|c|c|}
\hline Variables & \multicolumn{2}{|c|}{ Alive $(n=3 \mid 4)$} & \multicolumn{2}{|c|}{ Dead $(n=26)$} & p-value \\
\hline \multicolumn{6}{|l|}{$\mathrm{RC} 25 \mathrm{red}$} \\
\hline I & 17 & (5.4) & 11 & $(42.3)$ & $<0.001$ \\
\hline 2 & 31 & $(9.9)$ & 2 & (7.7) & \\
\hline 3 & 111 & $(35.4)$ & 7 & $(26.9)$ & \\
\hline 4 & 154 & $(49.0)$ & 6 & $(23.1)$ & \\
\hline 5 & 1 & $(0.3)$ & 0 & $(0.0)$ & \\
\hline Response time (min) & 6 & $(4-10)$ & 6.5 & $(5-8)$ & 0.927 \\
\hline$\leq 8$ & 213 & $(67.8)$ & 20 & $(76.9)$ & 0.338 \\
\hline$>8$ & 101 & $(32.2)$ & 6 & $(23.1)$ & \\
\hline On-scene time $(\mathrm{min})$ & 7 & $(4-9)$ & 8.5 & $(6-13)$ & 0.012 \\
\hline$\leq 10$ & 259 & $(82.5)$ & 16 & $(6 \mid .5)$ & 0.017 \\
\hline$>10$ & 55 & $(17.5)$ & 10 & $(38.5)$ & \\
\hline Distance from base station to scene $(\mathrm{km})$ & 2 & $(I-4)$ & 3 & $(I-4)$ & $0.48 \mathrm{I}$ \\
\hline Distance from scene to hospital $(\mathrm{km})$ & 2 & $(I-3)$ & 3 & $(I-4)$ & 0.270 \\
\hline Prehospital hemorrhage control & 132 & $(42.0)$ & 10 & $(38.5)$ & 0.722 \\
\hline Pressure dressing & 111 & $(35.4)$ & 10 & $(38.5)$ & 0.750 \\
\hline Dressing & 32 & $(10.2)$ & 0 & $(0.0)$ & 0.152 \\
\hline Prehospital airway management & 95 & $(30.3)$ & 21 & $(80.8)$ & $<0.001$ \\
\hline Mask with bag & 74 & $(23.6)$ & 3 & $(\mathrm{II} .5)$ & 0.159 \\
\hline Bag valve mask & 20 & (6.4) & 16 & $(6 I .5)$ & $<0.001$ \\
\hline Endotracheal tube & 2 & $(0.6)$ & 4 & $(15.4)$ & $<0.001$ \\
\hline Prehospital fluid management & 99 & $(3 \mid .5)$ & 17 & $(65.4)$ & $<0.001$ \\
\hline Ringer's lactate solution & 65 & $(20.7)$ & 14 & $(53.8)$ & $<0.001$ \\
\hline Normal saline solution & 30 & $(9.6)$ & 5 & $(19.2)$ & 0.167 \\
\hline Heparin lock & 1 & $(0.3)$ & 0 & $(0.0)$ & 1.000 \\
\hline Prehospital immobilization & 220 & $(70.1)$ & 19 & $(73.1)$ & 0.747 \\
\hline Prehospital cardiopulmonary resuscitation & 3 & $(\mathrm{l} .0)$ & II & $(42.3)$ & $<0.001$ \\
\hline
\end{tabular}

Notes: Data are presented as number (\%), mean \pm SD or median (interquartile range). P-values correspond to the independent sample t-test, Mann-Whitney U-test, Chisquare test, or Fisher exact test.

Abbreviations: bpm, beats per minute; NA, data not applicable; SD, standard deviation.

and the remainder died within the first 1-2 days. Secondly, the retrospective nature of this study meant that incomplete data were excluded. Thirdly, this was a singleinstitution study with a limited follow-up time (28 days) and included only patients transported to the emergency department at the Faculty of Medicine Vajira Hospital.
Therefore, our findings cannot be generalized to a broader population. Fourthly, pre-hospital factors and pre-hospital care could not be identified as factors associated with survival and severity of the injury had not been considered, which might affect survival. Finally, only prehospital factors from EMS patient care reports were 
Table 3 Univariable Analysis for Factors Associated with the Survival Rate of Traffic Accident Patients Transported by EMS

\begin{tabular}{|c|c|c|c|c|c|c|c|}
\hline Factors & \multicolumn{2}{|c|}{ Alive $(n=314)$} & \multicolumn{2}{|c|}{ Dead $(n=26)$} & OR & $95 \% \mathrm{Cl}$ & p-value \\
\hline \multicolumn{8}{|l|}{ Gender } \\
\hline Male & 223 & $(71.0)$ & 19 & $(73.1)$ & 1.00 & Reference & \\
\hline Female & 91 & $(29.0)$ & 7 & $(26.9)$ & 1.11 & $(0.45-2.73)$ & 0.824 \\
\hline Age (years), mean $\pm(S D)$ & \multicolumn{2}{|c|}{$37.33 \pm 16.99$} & \multicolumn{2}{|c|}{$33.85 \pm 17.00$} & 1.01 & $(0.99-1.04)$ & 0.317 \\
\hline \multicolumn{8}{|c|}{ Prehospital systolic blood pressure $(\mathrm{mmHg})$} \\
\hline$\leq 90$ & 19 & $(6.1)$ & 13 & $(50.0)$ & 1.00 & Reference & \\
\hline$>90$ & 295 & $(93.9)$ & 13 & $(50.0)$ & 15.53 & $(6.33-38.11)$ & $<0.001$ \\
\hline \multicolumn{8}{|c|}{ Prehospital heart rate (bpm) } \\
\hline$\leq 100$ & 213 & $(67.8)$ & 14 & $(53.8)$ & 1.00 & Reference & \\
\hline$>100$ & 101 & $(32.2)$ & 12 & $(46.2)$ & 0.55 & $(0.25-1.24)$ & 0.150 \\
\hline \multicolumn{8}{|c|}{ Prehospital oxygen saturation on room air } \\
\hline$\leq 94 \%$ & 52 & $(16.6)$ & 15 & $(57.7)$ & 1.00 & Reference & \\
\hline$>94 \%$ & 262 & $(83.4)$ & II & $(42.3)$ & 6.87 & $(2.99-15.8)$ & $<0.001$ \\
\hline \multicolumn{8}{|l|}{ Level of consciousness } \\
\hline Responsive & 293 & $(93.3)$ & 9 & $(34.6)$ & 1.00 & Reference & \\
\hline Unresponsive & 21 & $(6.7)$ & 17 & $(65.4)$ & 0.04 & $(0.02-0.10)$ & $<0.001$ \\
\hline \multicolumn{8}{|l|}{ Wounds } \\
\hline No & 29 & $(9.2)$ & 3 & $(11.5)$ & 1.00 & Reference & \\
\hline Yes & 285 & $(90.8)$ & 23 & $(88.5)$ & 1.28 & $(0.36-4.53)$ & 0.700 \\
\hline \multicolumn{8}{|l|}{ Orthopedic injuries } \\
\hline No & $|4|$ & $(44.9)$ & 12 & $(46.2)$ & 1.00 & Reference & \\
\hline Yes & 173 & $(55.1)$ & 14 & $(53.8)$ & 1.05 & $(0.47-2.35)$ & 0.902 \\
\hline \multicolumn{8}{|l|}{ Hemorrhage } \\
\hline No & 193 & $(6 \mid .5)$ & 14 & $(53.8)$ & 1.00 & Reference & \\
\hline Yes & 121 & $(38.5)$ & 12 & $(46.2)$ & 0.73 & $(0.33-1.63)$ & 0.446 \\
\hline \multicolumn{8}{|l|}{ Body part injured } \\
\hline Extremity & 209 & $(66.6)$ & 17 & $(65.4)$ & 1.05 & $(0.45-2.44)$ & 0.903 \\
\hline Head/neck & 170 & $(54.1)$ & 16 & $(6 \mid .5)$ & 0.74 & $(0.33-1.68)$ & 0.468 \\
\hline Face & 92 & $(29.3)$ & 15 & $(57.7)$ & 0.30 & $(0.14-0.69)$ & 0.004 \\
\hline Chest/clavicle & 37 & $(I I .8)$ & 6 & $(23.1)$ & 0.45 & $(0.17-1.18)$ & 0.104 \\
\hline External body surface & 27 & $(8.6)$ & 2 & $(7.7)$ & 1.13 & $(0.25-5.04)$ & 0.874 \\
\hline Pelvis & 27 & $(8.6)$ & 2 & $(7.7)$ & 1.13 & $(0.25-5.04)$ & 0.874 \\
\hline Multiple injuries & 24 & $(7.6)$ & 3 & $(11.5)$ & 0.63 & $(0.18-2.27)$ & 0.484 \\
\hline
\end{tabular}

(Continued) 
Table 3 (Continued).

\begin{tabular}{|l|l|l|l|l|l|l|l|}
\hline Factors & \multicolumn{2}{|l|}{ Alive $(\mathbf{n = 3 1 4 )}$} & \multicolumn{2}{l|}{ Dead $(\mathbf{n}=\mathbf{2 6})$} & OR & $\mathbf{9 5 \%} \mathbf{C l}$ & $\mathbf{p}$-value \\
\hline Abdomen & 22 & $(7.0)$ & 2 & $(7.7)$ & 0.90 & $(0.2-4.08)$ & 0.896 \\
\hline Spine & 18 & $(5.7)$ & 2 & $(7.7)$ & 0.73 & $(0.16-3.33)$ & 0.684 \\
\hline
\end{tabular}

Abbreviations: bpm, beats per minute; OR, odds ratio; $\mathrm{Cl}$, confidence interval; $\mathrm{NA}$, data not applicable.

Table 4 Univariable Analysis for the EMS Unit and Treatment Factors Associated with the Survival Rate of Traffic Accident Patients Transported by EMS

\begin{tabular}{|c|c|c|c|c|c|c|c|}
\hline Factors & \multicolumn{2}{|c|}{ Alive $(n=314)$} & \multicolumn{2}{|c|}{ Dead $(n=26)$} & OR & $95 \% \mathrm{Cl}$ & p-value \\
\hline \multicolumn{8}{|l|}{ RC 25 red } \\
\hline $\mathrm{I}-2$ & 48 & $(15.3)$ & 13 & $(50.0)$ & 1.00 & Reference & \\
\hline 3 & 111 & $(35.4)$ & 7 & $(26.9)$ & 4.30 & $(1.61-11.43)$ & 0.004 \\
\hline $4-5$ & 155 & $(49.4)$ & 6 & $(23.1)$ & 7.00 & $(2.52-19.40)$ & $<0.001$ \\
\hline \multicolumn{8}{|l|}{ Response time (min) } \\
\hline$\leq 8$ & 213 & $(67.8)$ & 20 & $(76.9)$ & 0.63 & $(0.25-1.62)$ & 0.341 \\
\hline$>8$ & 101 & $(32.2)$ & 6 & $(23.1)$ & 1.00 & Reference & \\
\hline \multicolumn{8}{|l|}{ On-scene time (min) } \\
\hline$\leq 10$ & 259 & $(82.5)$ & 16 & $(61.5)$ & 2.94 & $(1.27-6.83)$ & 0.012 \\
\hline$>10$ & 55 & $(17.5)$ & 10 & $(38.5)$ & 1.00 & Reference & \\
\hline Distance from base station to scene $(\mathrm{km})$ & 2 & $(1-4)$ & 3 & $(1-4)$ & 0.93 & $(0.77-1.13)$ & 0.472 \\
\hline Distance from scene to hospital $(\mathrm{km})$ & 2 & $(I-3)$ & 3 & $(I-4)$ & 0.92 & $(0.75-1.14)$ & 0.459 \\
\hline \multicolumn{8}{|l|}{ Prehospital hemorrhage control } \\
\hline No & 182 & $(58.0)$ & 16 & $(61.5)$ & 1.00 & Reference & \\
\hline Yes & 132 & $(42.0)$ & 10 & $(38.5)$ & 1.16 & $(0.5 I-2.64)$ & 0.723 \\
\hline \multicolumn{8}{|l|}{ Prehospital airway management } \\
\hline No & 219 & $(69.7)$ & 5 & $(19.2)$ & 1.00 & Reference & \\
\hline Yes & 95 & $(30.3)$ & 21 & $(80.8)$ & 0.10 & $(0.04-0.28)$ & $<0.001$ \\
\hline \multicolumn{8}{|l|}{ Prehospital fluid management } \\
\hline No & 215 & $(68.5)$ & 9 & $(34.6)$ & 1.00 & Reference & \\
\hline Yes & 99 & $(31.5)$ & 17 & $(65.4)$ & 0.24 & $(0.11-0.57)$ & 0.001 \\
\hline \multicolumn{8}{|l|}{ Prehospital immobilization } \\
\hline No & 94 & $(29.9)$ & 7 & $(26.9)$ & 1.00 & Reference & \\
\hline Yes & 220 & $(70.1)$ & 19 & $(73.1)$ & 0.86 & $(0.35-2.12)$ & 0.747 \\
\hline \multicolumn{8}{|l|}{ Prehospital cardiopulmonary resuscitation } \\
\hline No & 311 & $(99.0)$ & 15 & $(57.7)$ & 1.00 & Reference & \\
\hline Yes & 3 & $(1.0)$ & II & $(42.3)$ & 0.01 & $(0.01-0.05)$ & $<0.001$ \\
\hline
\end{tabular}

Abbreviations: bpm, beats per minute; OR, odds ratio; $\mathrm{Cl}$, confidence interval; NA, data not applicable. 
Table 5 Univariable Analysis and Multivariable Analysis of Factors Associated with the Survival Rate of Traffic Accident Patients Transported by the EMS

\begin{tabular}{|c|c|c|c|c|c|c|}
\hline \multirow[t]{2}{*}{ Factors } & \multicolumn{3}{|c|}{ Univariable Analysis } & \multicolumn{3}{|c|}{ Multivariable Analysis } \\
\hline & $\mathbf{O} \mathbf{R}^{\mathbf{a}}$ & $95 \% \mathrm{Cl}$ & p-value & $\mathbf{O R}_{\mathrm{adj}} \mathbf{b}^{\mathbf{b}}$ & $95 \% \mathrm{Cl}$ & p-value \\
\hline \multicolumn{7}{|c|}{ Prehospital systolic blood pressure $(\mathrm{mmHg})$} \\
\hline$\leq 90$ & 1.00 & Reference & & & & \\
\hline$>90$ & 15.53 & $(6.33-38.11)$ & $<0.001$ & & & \\
\hline \multicolumn{7}{|c|}{ Prehospital oxygen saturation on room air } \\
\hline$\leq 94 \%$ & 1.00 & Reference & & & & \\
\hline$>94 \%$ & 6.87 & $(2.99-15.8)$ & $<0.001$ & & & \\
\hline \multicolumn{7}{|c|}{ Prehospital level of consciousness } \\
\hline Responsive & 1.00 & Reference & & 1.00 & Reference & \\
\hline Unresponsive & 0.04 & $(0.02-0.10)$ & $<0.001$ & 0.16 & $(0.05-0.56)$ & 0.004 \\
\hline \multicolumn{7}{|l|}{ Body part injured } \\
\hline Face & 0.30 & $(0.14-0.69)$ & 0.004 & & & \\
\hline \multicolumn{7}{|l|}{ RC 25 red } \\
\hline $1-2$ & 1.00 & Reference & & & & \\
\hline 3 & 4.30 & $(1.6 I-11.43)$ & 0.004 & & & \\
\hline $4-5$ & 7.00 & $(2.52-19.40)$ & $<0.001$ & & & \\
\hline \multicolumn{7}{|c|}{ On-scene time $(\mathrm{min})$} \\
\hline$\leq 10$ & 2.94 & $(1.27-6.83)$ & 0.012 & & & \\
\hline$>10$ & 1.00 & Reference & & & & \\
\hline \multicolumn{7}{|c|}{ Prehospital airway management } \\
\hline No & 1.00 & Reference & & 1.00 & Reference & \\
\hline Yes & 0.10 & $(0.04-0.28)$ & $<0.001$ & 0.30 & $(0.09-0.97)$ & 0.045 \\
\hline \multicolumn{7}{|c|}{ Prehospital fluid management } \\
\hline No & 1.00 & Reference & & & & \\
\hline Yes & 0.24 & $(0.11-0.57)$ & 0.001 & & & \\
\hline \multicolumn{7}{|c|}{ Prehospital cardiopulmonary resuscitation } \\
\hline No & 1.00 & Reference & & 1.00 & Reference & \\
\hline Yes & 0.01 & $(0.0 \mathrm{I}-0.05)$ & $<0.001$ & 0.10 & $(0.02-0.47)$ & 0.004 \\
\hline
\end{tabular}

Notes: ${ }^{a}$ Crude $O R$ estimated by binary logistic regression. ${ }^{b} O R_{a d j}$ estimated by multiple logistic regression.

Abbreviations: $\mathrm{OR}$, odds ratio; $\mathrm{OR}_{\mathrm{adj}}$, adjusted odds ratio; $\mathrm{Cl}$, confidence interval.

analyzed, and no data from the emergency department, operating theater, or other in-hospital treatments were included.

\section{Conclusion}

We observed a high survival rate of $92.35 \%$ in our cohort of traffic accident patients. In the context of traffic 
accident patients managed by EMS, we identified three factors that were related to increased survival: a prehospital responsive level of consciousness, no prehospital airway management, and no prehospital cardiopulmonary resuscitation.

\section{Abbreviations}

ALS, advanced life support; EMR, electronic medical record; EMS, emergency medical services; EMTs, emergency medical technicians; ENPs, emergency nurse practitioner; EPs, emergency physicians; IDCC, Injury Data Collaboration Center; ITEMS, Information Technology for Emergency Medical System; MVC, motor vehicle crash; S.M.A.R.T, Surgico Medical Ambulance and Rescue Team; WHO, World Health Organization.

\section{Data Sharing Statement}

The data that support the findings of this study are available from the corresponding author upon reasonable request.

\section{Acknowledgments}

The authors are grateful to Mr. Tavachai Soion, Deputy Chief of the Division of Emergency Medical Service and Disaster, and Dr. Chunlanee Sangketchon, Chief of the Department of Disaster and Emergency Medical Operation, for always assisting and facilitating research, and Dr. Aniwat Berpan for acting as an English consultant for this study.

\section{Author Contributions}

All authors made a significant contribution to the work reported, whether that is in the conception, study design, execution, acquisition of data, analysis and interpretation, or in all these areas; took part in drafting, revising or critically reviewing the article; gave final approval of the version to be published; have agreed on the journal to which the article has been submitted; and agree to be accountable for all aspects of the work.

\section{Funding}

The research was funded by Navamindradhiraj University.

\section{Disclosure}

The authors report no conflicts of interest in this work.

\section{References}

1. World Health Organization. Global situation report on road safety 2015; 2015 [cited May 5, 2021]. Available from: https://www.afro. who.int/sites/default/files/2017-06/summary\%20thailand.pdf. Accessed December 8, 2021.

2. Sadeghi-Bazargani H, Sadeghpour A, Lowery Wilson M, Ala A, Rahmani F. Developing a national integrated road traffic injury registry system: a conceptual model for a multidisciplinary setting. $J$ Multidiscip Healthc. 2020;13:983-996. doi:10.2147/JMDH. S262555

3. National Institute for Emergency Medicine. Performance of the emergency medical service system. [cited May 5, 2021]. Available from: https://ws.niems.go.th/ITEMS_DWH/. Accessed December 7, 2021.

4. Injury Data Collaboration Center Division of Injury Prevention: IDCC. The graph shows the number of injuries and deaths Year 2015-2020;2020 [cited May 5, 2021]. Available from: http://dip.ddc.moph.go.th/new/\% E0\%B8\%9A\%E0\%B8\%A3\%E0\%B8\%B4\%E0\%B8\%81\%E0\%B8\% B2\%E0\%B8\%A3/43-acc. Accessed December 8, 2021.

5. Blomberg H, Svennblad B, Michaelsson K, Byberg L, Johansson J, Gedeborg R. Prehospital trauma life support training of ambulance caregivers and the outcomes of traffic-injury victims in Sweden. $J$ Am Coll Surg. 2013;217:1010-1019. doi:10.1016/j.jamcollsurg.2013.08.002

6. Şan İ, Usul E, Bekgöz B, Korkut S. Effects of COVID-19 pandemic on emergency medical services. Int J Clin Pract. 2021;75:e13885. doi:10.1111/ijcp.13885

7. Murad MK, Larsen S, Husum H. Prehospital trauma care reduces mortality. Ten-year results from a time-cohort and trauma audit study in Iraq. Scand J Trauma Resusc Emerg Med. 2012;20(13):7. doi:10.1186/1757-7241-20-13

8. Yeguiayan J-M, Garrigue D, Binquet C, et al. Medical pre-hospital management reduces mortality in severe blunt trauma: a prospective epidemiological study. Crit Care. 2011;15(1):34. doi:10.1186/cc9982

9. Jarman MP, Porter KP, Curriero FC, Castillo RC. Factors mediating demographic determinants of injury mortality. Ann Epidemiol. 2019;34:58-64. doi:10.1016/j.annepidem.2019.03.013

10. Gauss T, Ageron FX, Devaud ML, et al. Association of prehospital time to in-hospital trauma mortality in a physician-staffed emergency medicine system. JAMA Surg. 2019;154:1117-1124. doi:10.1001/ jamasurg.2019.3475

11. Harmsen A, Giannakopoulos GF, Moerbeek PR, Jansma EP, Bonjer H, Bloemers FW. The influence of prehospital time on trauma patients outcome: a systematic review. Injury. 2015;46:602-609. doi:10.1016/j.injury.2015.01.008

12. Byrne JP, Mann NC, Dai M, et al. Association between emergency medical service response time and motor vehicle crash mortality in the United States. JAMA Surg. 2019;154:286-293. doi:10.1001/ jamasurg.2018.5097

13. Huang CY, Rau CS, Chuang JF, et al. Characteristics and outcomes of patients injured in road traffic crashes and transported by emergency medical services. Int $J$ Environ Res Public Health. 2016;13:236. doi:10.3390/ijerph13020236

14. Daniel WW. Biostatistics: A Foundation for Analysis in the Health Sciences. 6th ed. John Wiley\&Sons, Inc.; 1995.

15. Mahama MN, Kenu E, Bandoh DA, Zakariah AN. Emergency response time and pre-hospital trauma survival rate of the National ambulance service, greater Accra (January-December 2014). BMC Emerg Med. 2018;18:1-7. doi:10.1186/s12873-018-0184-3

16. Bernard R. Fundamentals of Biostatistics. Vol. 5. Duxbury: Thomson learning; 2000.

17. Textbook of Clinical Research. 4th ed. Bangkok: Faculty of Tropical Medicine, Mahidol University; 2011.

18. National Institute for Emergency Medicine. Guidelines for Emergency Triage Education and Practice in Thailand 2011 Journals. Bangkok: Beyond publishing; 2015:1-38. 
19. Wongvatanakij P, Tadadej C, Meyai A, Suriyawongpaisal P. Relation of factor on survival outcomes among traumatic patients at the tertiary care hospital admitted for traffic accidents in Phuket Province. Srinagarind Med J. 2019;34:52-59.

20. Tesfay K, Assefa M, Zenebe D, Gebremicael M, Kebede G, Gebrekirstos H. Road traffic injured patients with severe GCS and organ injury had a poor prognosis: a retrospective cohort study. $B M C$ Public Health. 2019;19:749. doi:10.1186/s12889-019-7100-y

21. Seid M, Azazh A, Enquselassie F, Yisma E. Injury characteristics and outcome of road traffic accident among victims at Adult Emergency Department of Tikur Anbessa specialized hospital, Addis Ababa, Ethiopia: a prospective hospital based study. BMC Emerg Med. 2015;15:10. doi:10.1186/s12873-015-0035-4

22. Huabbangyang T, Soion T, Promdee A, et al. Factors associated with successful resuscitation during out-of-hospital cardiac arrest performed by Surgico Medical Ambulance and Rescue Team (S.M.A. R.T), Division of Emergency Medical Service and Disaster, Faculty of Medicine Vajira Hospital, Navamindradhiraj University. $J$ Med Assoc Thai. 2021;104:1-9.

23. Hoffmann M, Czorlich P, Lehmann W, Spiro AS, Rueger JM, Lefering R. The impact of prehospital intubation with and without sedation on outcome in trauma patients with a GCS of 8 or less. J Neurosurg Anesthesiol. 2017;29:161-167. doi:10.1097/ANA.0000000000000275
24. Denninghoff KR, Nuño T, Pauls Q, et al. Prehospital intubation is associated with favorable outcomes and lower mortality in ProTECT III. Prehosp Emerg Care. 2017;21:539-544. doi:10.1080/ 10903127.2017.1315201

25. Dorlac WC, DeBakey ME, Holcomb JB, et al. Mortality from isolated civilian penetrating extremity injury. $J$ Trauma. 2005;59:217-222. doi:10.1097/01.TA.0000173699.71652.BA

26. Stewart CL, Holscher CM, Moore EE, et al. Base deficit correlates with mortality in pediatric abusive head trauma. $J$ Pediatr Surg. 2013;48:2106-2111. doi:10.1016/j.jpedsurg.2013.05.009

27. Stockinger ZT, McSwain NE Jr. Additional evidence in support of withholding or terminating cardiopulmonary resuscitation for trauma patients in the field. J Am Coll Surg. 2004;198:227-231. doi:10.1016/ j.jamcollsurg.2003.10.012

28. Alanezi K, Alanzi F, Faidi S, et al. Survival rates for adult trauma patients who require cardiopulmonary resuscitation. CJEM. 2004;6:263-265. doi:10.1017/S1481803500009234

\section{Publish your work in this journal}

The Open Access Emergency Medicine is an international, peerreviewed, open access journal publishing original research, reports, editorials, reviews and commentaries on all aspects of emergency medicine. The manuscript management system is completely online and includes a very quick and fair peer-review system, which is all easy to use. Visit http://www.dovepress.com/testimonials.php to read real quotes from published authors. 